\title{
TGA-FTIR CHARACTERISATION OF BAMBOO WOOD, NAPIER GRASS, PINE WOOD AND PEACH PIPS FOR GASIFICATION APPLICATIONS
}

\author{
Nkateko P. Makaringe ${ }^{1 *}$, Izak J. van der Walt ${ }^{1}$, Gerard J. Puts², Philippus L. Crouse ${ }^{2}$ \\ ${ }^{1}$ The South African Nuclear Energy Corporation SOC Ltd. Pelindaba, North West Province South Africa. \\ 2Department of Chemical Engineering, Faculty of Engineering, Build Environment \& IT, University of Pretoria, Pretoria, South Africa; \\ *Corresponding author Tel.:+27 12305 6170; Fax: +27 12305 3197; E-mail address:nkateko.makaringe@necsa.co.za
}

$\begin{array}{ll}\text { Acepted } & 03 / 01 / 2017 \\ \text { Published in } & 01 / 03 / 2017\end{array}$

Keywords

Biomass pyrolysis

TGA kinetic

TGA-FTIR

green energy

DOI 10.18362/bjta.v6.i1.8

\begin{abstract}
The pyrolysis characteristics of four biomass materials (bamboo, Napier grass, pine and peach pips) were studied in an inert atmosphere using a simultaneous TGA-FTIR instrument. The behaviour of these materials under non-isothermal conditions and at three different heating rates $\left(20,100\right.$ and $\left.200{ }^{\circ} \mathrm{C} / \mathrm{min}\right)$ were compared. The gasses released during TGA analysis were analysed using inline FTIR. Higher heating rates were found to increase conversion and had lower activation energies. Napier grass has the lowest conversion which could be due to the amount of silicon contained in most grasses. A distinguishable hemicellulose decomposition peak was detected on the DTG curve of the peach pips. Pine wood has the highest conversion ( $88 \%)$ of the four biomass materials. The mean conversion achieved for the other materials was approximately $75 \%$. The kinetic parameters of each material computed using a model fitting method are reported. The dehydration stage in general displayed lower activation energies than the active and passive pyrolysis stages.
\end{abstract}

Introduction

Energy demand has increased significantly in recent years due population increase and the concomitant increase in urban and industrial development worldwide [8, 17]. Since fossil fuels are the largest single global energy source, energy shortages have developed in countries with a paucity of fossil resources. Although fuel like coal is available in abundance in some countries, its availability worldwide will soon be exhausted [6], considering that it is also used in petrochemical and metallurgical industries. Moreover due to high demand, fossil fuel prices have increased significantly over the last ten years. More importantly, today climate change is a major environmental problem resulting from carbon dioxide $\left(\mathrm{CO}_{2}\right)$ emission when using these fossil fuels are combusted [4]. The current emission of $\mathrm{CO}_{2}$ must be reduced by at least $40-70 \%$ before the year 2050 in order to limit the global warming to below $2{ }^{\circ} \mathrm{C}$ [28]. Concentration of $\mathrm{CO}_{2}$ in the atmosphere will continue to rise unless major changes are made in the way fossil fuels are used to provide energy [2]. As a solution to $\mathrm{CO}_{2}$ emission problem, there is a call for the reduction of greenhouse gas concentrations to a level that would prevent dangerous anthropogenic interference with climate system. In response to this call, other, cleaner sources of energy such as biomass are being explored. Compared to other alternative energy sources such as nuclear energy, biomass is an energy source of interest due to its renewability $[5,21,26]$ and also because it can be generated locally and makes any non-petroleum-producing country less depended on foreign imports [11].
The biggest challenge with respect to biomass is finding an effective method for its utilisation. Many methods such as pyrolysis and gasification are being developed worldwide with the aim of increasing biomass conversion to liquid and gaseous fuels like synthesis gas. For such developments, it is of imperative to understand the physical and chemical characteristics of biomass prior to application.

In general, biomass contains mainly the elements carbon $(\mathrm{C})$, hydrogen $(\mathrm{H})$ and oxygen $(\mathrm{O})$ and consists of three major components, viz.: cellulose, hemicellulose and lignin. Biomass materials are, however, diverse and their composition highly variable [23]. Due to this variability in properties and composition, the approximate and ultimate analyses are performed on materials of interest [19]. There are various factors that influence the composition of biomass. The origin of the material [7], the type of the material, and the part of the plant (i.e. leaves, stems, seeds or roots) are a few of the factors influencing the composition of biomass [23]. The properties of biomass material van further be classified as woody, herbaceous, aquatic, or manure, as well as contaminated and industrial biomass (forming part of municipal waste) [14, 23]. Of all these groups the focus for utilisation is more on the woody and herbaceous biomass due to their lower moisture content [14].

Clearly it should not be assumed that all biomass material will give the same results during their utilisation. Hence it is important to conduct characterisation studies for each biomass material in question. Thermogravimetric analysis (TGA) and other thermal techniques such as differential scanning calorimetry (DSC), differential thermal analysis (DTA), are commonly used 
$[1,8,11,12,21]$. In this study characteristics of four types of biomass, viz. bamboo, Napier grass, pine chips and peach pips were investigated.

A thermogravimetric analyser coupled to a Fourier transform infrared spectrometer (TGA-FTIR) was used in this study to monitor the mass loss of these materials heated at different heating rates in an inert nitrogen flow. The results obtained were also used to compute the degradation kinetics of each material. The four materials used in this study were selected because, at the time of this study, they were being used in the development of laboratory scale biomass plasma gasification systems. The results obtained during this study will be used in the optimisation of these gasification systems.

\section{Materials and methods}

\section{Material}

Biomass samples used in this work were Napier grass (Pennisetum pupureum), Peach pips (Prunus persica (L.) Batsch), Bamboo wood (Bambusa balcooa) and Pine wood (Pinus patula). All samples were sourced from local suppliers of forestry products, except the bamboo, which was taken from the University' of Pretoria's botanical garden. Nitrogen gas (>99.999\%) was obtained from African Oxygen Ltd. And used as received.

\section{Sample preparation}

The biomass samples were prepared by first cutting the material into small pieces and then by milling using a Retsch mill (Type SR 200, Model 70546). The samples were further sieved in order to obtain a fine fraction.

\section{Thermogravimetric analysis}

The TGA-FTIR analysis was performed using a Perkin Elmer TGA 4000 coupled to a Perkin Elmer Spectrum 100 FTIR spectrometer. The gases evolved from the TGA were transferred to a heated infrared cell (kept at $250^{\circ} \mathrm{C}$ ) via a heated stainless steel transfer line (kept at $250^{\circ} \mathrm{C}$ ). The IR cell was fitted with $\mathrm{KBr}$ single crystal windows and had a beam path length of $10 \mathrm{~cm}$.

For each TGA experiment, approximately $20 \mathrm{mg}$ of sample was placed in an a-alumina crucible. The TG curves were recorded from $\sim 25^{\circ} \mathrm{C}$ to $950{ }^{\circ} \mathrm{C}$ at three different heating rates, viz.: 20,100 and $200{ }^{\circ} \mathrm{C} / \mathrm{min}$ under nitrogen atmosphere flowing at a rate of $20 \mathrm{~mL} / \mathrm{min}$, then kept isothermal for 15 minutes. The end temperature is close to the operating temperature of gasification system.

The FTIR spectrometer was set to scan from $4000 \mathrm{~cm}^{-}$ 1 to $550 \mathrm{~cm}^{-1}$ at a rate of one spectrum every 6 seconds with frequency resolution of $1 \mathrm{~cm}^{-1}$.

\section{Kinetic model development}

The kinetic parameters can be calculated using either model fitting or model-free (isoconventional) methods [10]. The isoconventional method is widely used in the field of biomass pyrolysis due to its ability to calculate activation energy values without model assumptions [6, 25, 26]. Model-free methods require a set of experimental tests at different heating rates, and do not calculate a frequency factor $(A)$ but it only report the activation energy $\left(E_{a}\right)[9]$. The model fitting method estimates the full kinetic triplet, i.e. the model, its parameters, along with $A$ and $E_{a}$. A model fitting method was chosen for this study.

The approach taken is as follows [24]: The rate can be parameterised in terms of three major variables, i.e. the temperature $T$, the extent of conversion $\alpha$, and pressure $P$ according to

$$
\frac{d \alpha}{d t}=k(T) f(\alpha) h(P)
$$

Here $t$ is time. In most areas of thermal analysis, pressure effects are ignored. Similarly, pressure effects were neglected in this study, and the two-variable form of Equation 1 was used

$$
\frac{d \alpha}{d t}=k(T) f(\alpha)
$$

The extent of conversion $\alpha$ is defined as

$$
\alpha=\frac{m_{0}-m_{t}}{m_{0}-m_{\infty}}
$$

The factor $k(T)$ in Equation 2 is the rate constant; and represents the temperature dependence, expressed by the Arrhenius equation

$$
k(T)=A \exp \left(\frac{-E_{a}}{R T}\right)
$$

$\mathrm{R}$ is the universal gas constant. The model $f(\alpha)$ can in general take of three forms, viz: accelerating, decelerating, or sigmoidal. In most biomass kinetic studies the reaction model is expressed in term of the deceleration model [6, 16] where the rate has a maximum at the beginning of the process and decreases continually as the extent of conversion increases. Only those kinetic methods that are capable of treating all three types of the conversion dependencies can be regarded as reliable [24]. The Sestak-Berggren equation, (Equation 5), which accommodates all three functionalities, is an example of such a model $[3,18]$

$$
f(\alpha)=\alpha^{m}(1-\alpha)^{n}[-\ln (1-\alpha)]^{p}
$$

Here $n, m$ and $p$ are constants. Substitution of Equations 4 and 5 into 2 gives

$$
\frac{d \alpha}{d t}=A \exp \left(\frac{-E_{a}}{R T}\right) \alpha^{m}(1-\alpha)^{n}[-\ln (1-\alpha)]^{p}
$$


Braz. J. Therm. Anal. Vol. 6 No. 1

Application of the chain rule to the left-hand term of Equation 2, and division by the heating rate, $\beta=d T / d t$, yields

$$
\frac{d \alpha}{d T}=\frac{1}{\beta} A \exp \left(\frac{-E_{a}}{R T}\right) \alpha^{m}(1-\alpha)^{n}[-\ln (1-\alpha)]^{p}
$$

The kinetics parameters can be estimated from Equation 7 by direct fitting of the equation to each TG curve. We found the rate expression to be mathematically uncomplicated, and a simple Euler integration was used for curve fitting, viz.

$$
\alpha_{i+1}=\alpha_{i}+\frac{1}{\beta} A \exp \left(\frac{-E_{a}}{R T_{i}}\right) \alpha_{i}^{m}\left(1-\alpha_{i}\right)^{n}\left[-\ln \left(1-\alpha_{i}\right)\right]^{p} \delta T
$$

Here $i$ refers an individual step along the TG curves. The fitting process comprised computation of model values for each step on the TG curves for $0.05<\alpha<0.95$, and iteratively adjusting the parameters $n, m$ and $p, A$ and $E_{a}$ to minimize the $\mathrm{SSD}$, i.e. the sum of the square of the differences between computed and experimental step values.

Biomass pyrolysis was found to be a three-step process, each with its own model and model parameters. In order to handle this, the procedure above had to be modified. For the Sestak-Berggren equation to work, we found it necessary for $\alpha$ to have a large range of values, as close to $0-1$ as possible. Each the TG curves thus had to be split into three discreet thermal events, each with its own $\alpha$, in the range $0.05<\alpha<0.95$, defined as

$$
\alpha_{j}=\frac{m_{0, j}-m_{j}}{m_{0, j}-m_{0, j+1}}
$$
thermal event.

The zero subscript refers to the initial value for the jth

\section{Results and discussion}

\section{Results}

The TG curves for bamboo at the three selected heating rates are presented in

Figure 1, and their first derivative curves are presented in Figure 2. The TG curves for the four biomass samples heated at $200{ }^{\circ} \mathrm{C} / \mathrm{min}$ are presented in

Figure 3 and their first derivative curves are presented in Figure 4. The time resolved infrared spectra for the gases produced by bamboo heated at $20{ }^{\circ} \mathrm{C} / \mathrm{min}$, taken at various temperatures are presented in Figure 5. The FTIR spectrum peak areas for the active pyrolysis stage (aps) at a heating rate of $200^{\circ} \mathrm{C} / \mathrm{min}$ are presented in

Table 2. The kinetic model fitting graphs for bamboo at $20{ }^{\circ} \mathrm{C} / \mathrm{min}$ are displayed in Figure 6 , and the kinetic model
DOI 10.18362/bjta.v6.i1

parameters for kinetic parameters equation are reported in Table 3 to

Table 6.

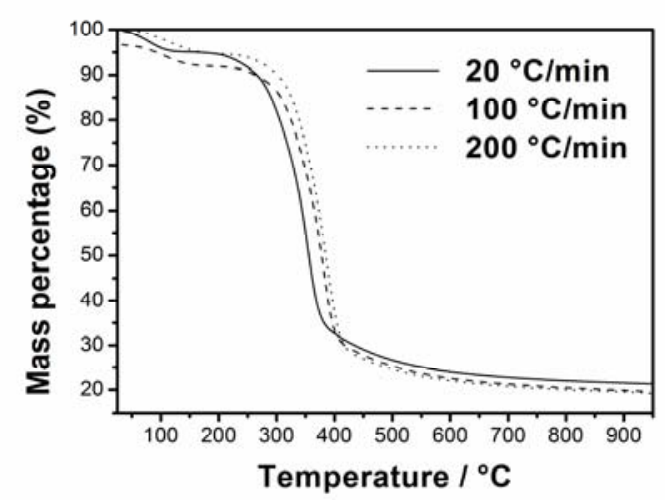

Figure 1. TGA curves of bamboo at 20,100 and $200{ }^{\circ} \mathrm{C} /$ min under nitrogen.

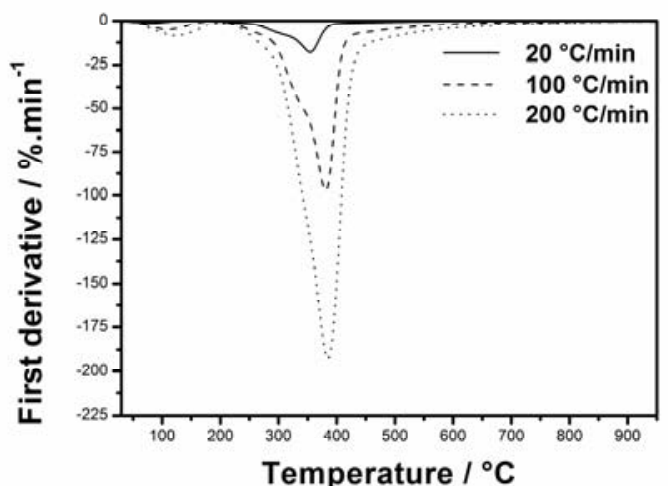

Figure 2. DTG Curves of bamboo heated at 20,100 and $200{ }^{\circ} \mathrm{C} / \mathrm{min}$ under nitrogen

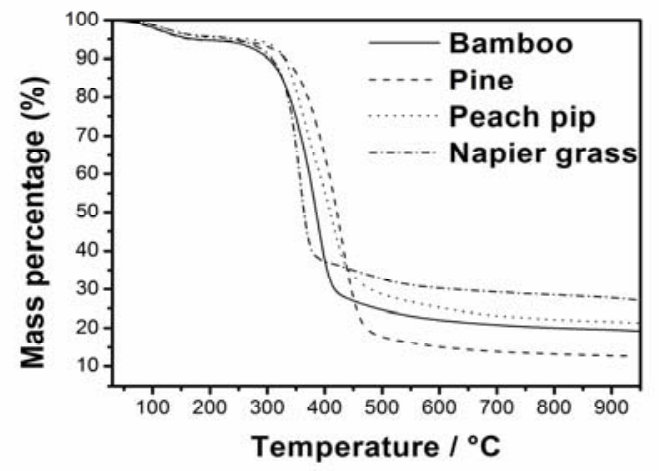

Figure 3. Comparison of the thermal decomposition behaviour of bamboowood, pine wood, peach pip and Napier grass at $200^{\circ} \mathrm{C} / \mathrm{min}$ under a nitrogen flow. 


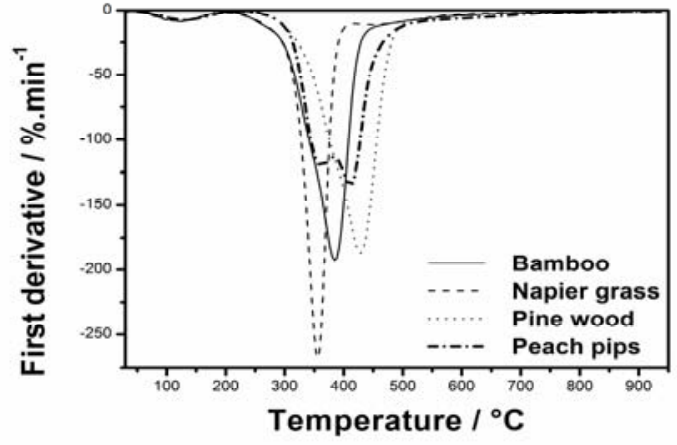

Figure 4. DTG Curves for bamboo, Napier grass, pine wood and peach pips heated at $200^{\circ} \mathrm{C} / \mathrm{min}$ under a nitrogen flow.

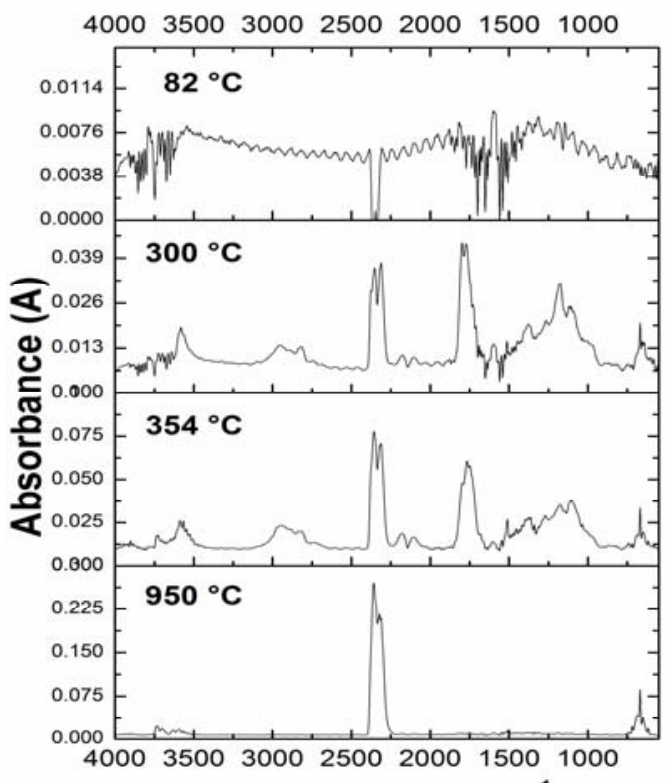

Frequency $/ \mathrm{cm}^{-1}$
Table 2: FTIR spectrum peak areas for active pyrolysis stage at a heating rate of $200^{\circ} \mathrm{C} / \mathrm{min}$

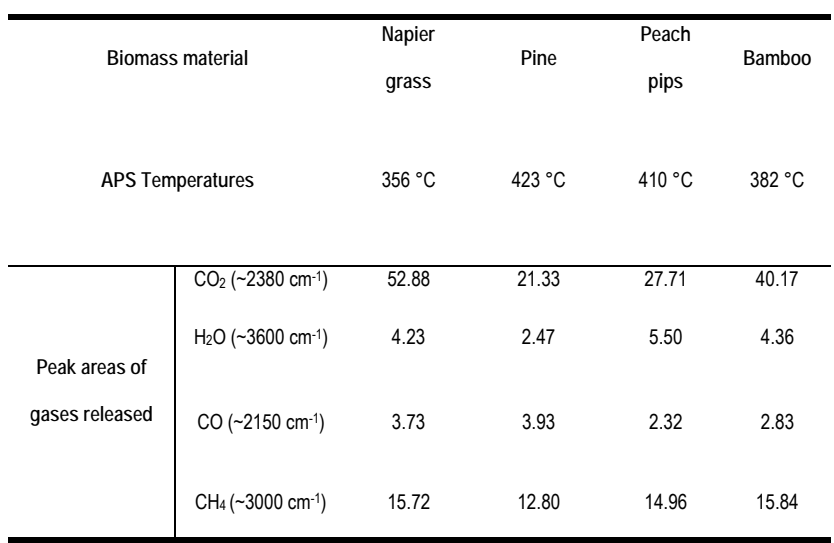

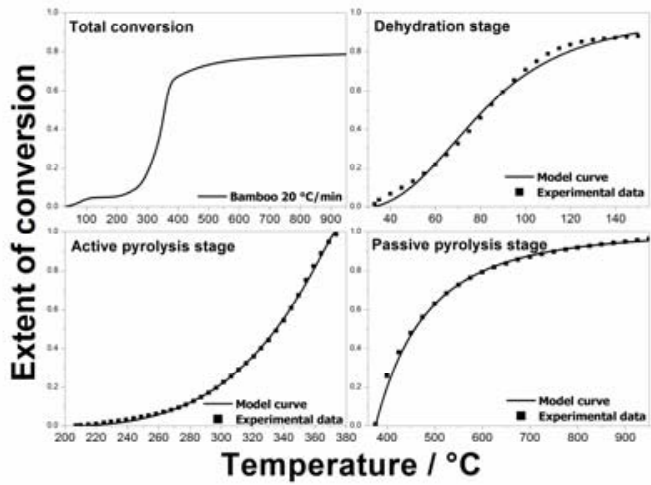

Figure 6. Experimental and predicted $\alpha-T$ curves of bamboo at a heating rate of $20^{\circ} \mathrm{C} / \mathrm{min}$.

Table 3: Kinetic model parameters for the thermal decomposition of peach pips.

\begin{tabular}{|c|c|c|c|c|c|c|c|c|c|}
\hline \multicolumn{10}{|c|}{ Peach pips } \\
\hline \multicolumn{2}{|l|}{$\beta\left({ }^{\circ} \mathrm{C} / \mathrm{min}\right)$} & \multicolumn{2}{|l|}{20} & \multicolumn{3}{|c|}{100} & \multicolumn{3}{|c|}{200} \\
\hline Stages & 1 & 2 & 3 & 1 & 2 & 3 & 1 & 2 & 3 \\
\hline$E_{a}(\mathrm{~kJ} / \mathrm{mol})$ & 16.97 & 20.63 & 25.80 & 11.31 & 13.08 & 9.91 & 9.44 & 12.05 & 4.43 \\
\hline$A\left(\mathrm{~min}^{-1}\right)$ & 208.78 & 55.11 & 50.19 & 89.89 & 60.94 & 20.10 & 85.59 & 69.81 & 27.38 \\
\hline$m$ & 0.00 & 0.05 & 0.00 & 0.03 & 0.05 & 0.28 & 0.03 & 0.05 & 0.454 \\
\hline$n$ & 1.12 & 1.01 & 2.19 & 1.11 & 0.49 & 1.84 & 1.42 & 0.00 & 2.12 \\
\hline$p$ & 0.46 & 0.63 & 0.00 & 0.61 & 0.72 & 0.00 & 0.68 & 0.66 & 0.018 \\
\hline SSD & 3.80 & 3.20 & 29.70 & 0.23 & 0.70 & 4.31 & 0.65 & 0.48 & 1.57 \\
\hline
\end{tabular}


Table 4: Kinetic model parameters for the thermal decomposition of Napier grass.

\begin{tabular}{|c|c|c|c|c|c|c|c|c|c|}
\hline \multicolumn{10}{|c|}{ Napier } \\
\hline$\beta\left({ }^{\circ} \mathrm{C} / \mathrm{min}\right)$ & & 20 & & & 100 & & & 200 & \\
\hline Stages & 1 & 2 & 3 & 1 & 2 & 3 & 1 & 2 & 3 \\
\hline$E_{a}(\mathrm{~kJ} / \mathrm{mol})$ & 13.67 & 23.80 & 29.13 & 13.18 & 15.95 & 16.214 & 10.70 & 12.95 & 10.7 \\
\hline$A\left(\min ^{-1}\right)$ & 98.04 & 55.70 & 44.95 & 157.80 & 62.71 & 21.4 & 158.44 & 67.76 & 21.1 \\
\hline$m$ & 0.03 & 0.50 & 0.00 & 0.03 & 0.05 & 0.00 & 0.03 & 0.05 & 0.19 \\
\hline$n$ & 1.78 & 0.31 & 3.64 & 1.11 & 0.26 & 4.24 & 1.37 & 0.27 & 4.57 \\
\hline$p$ & 0.57 & 0.49 & 0.00 & 0.56 & 0.63 & 0.00 & 0.73 & 0.62 & 0.136 \\
\hline SSD & 6.80 & 4.62 & 129.81 & 0.53 & 1.19 & 3.74 & 0.89 & 1.02 & 1.44 \\
\hline
\end{tabular}

Table 5: Kinetic model parameters for the thermal decomposition of pine wood.

\begin{tabular}{|c|c|c|c|c|c|c|c|c|c|}
\hline \multicolumn{10}{|c|}{ Pine } \\
\hline$\beta\left({ }^{\circ} \mathrm{C} / \mathrm{min}\right)$ & & 20 & & & 100 & & & 200 & \\
\hline Stages & 1 & 2 & 3 & 1 & 2 & 3 & 1 & 2 & 3 \\
\hline$E_{a}(\mathrm{~kJ} / \mathrm{mol})$ & 16.41 & 26.44 & 19.542 & 14.84 & 19.13 & 56.34 & 12.83 & 14.94 & 9.66 \\
\hline$A\left(\mathrm{~min}^{-1}\right)$ & 210.05 & 52.40 & 20.55 & 267.19 & 64.99 & 81884. & 238.03 & 60.95 & 26.84 \\
\hline$m$ & 0.05 & 0.05 & 0.00 & 0.07 & 0.05 & 0.00 & 0.19 & 0.05 & 0.00 \\
\hline$n$ & 1.19 & 0.33 & 2.72 & 1.00 & 0.41 & 3.5 & 1.03 & 0.53 & 2.60 \\
\hline$p$ & 0.45 & 0.47 & 0.00 & 0.46 & 0.54 & 0.00 & 0.44 & 0.61 & 0.00 \\
\hline SSD & 5.47 & 1.57 & 27.65 & 0.50 & 0.30 & 1.37 & 0.27 & 0.12 & 1.18 \\
\hline
\end{tabular}

Table 6: Kinetic model parameters for the thermal decomposition of bamboo wood.

\begin{tabular}{|c|c|c|c|c|c|c|c|c|c|}
\hline \multicolumn{10}{|c|}{ Bamboo } \\
\hline$\beta\left({ }^{\circ} \mathrm{C} / \mathrm{min}\right)$ & \multicolumn{3}{|c|}{20} & \multicolumn{3}{|c|}{100} & \multicolumn{3}{|c|}{200} \\
\hline Stages & 1 & 2 & 3 & 1 & 2 & 3 & 1 & 2 & 3 \\
\hline$E_{a}(\mathrm{KJ} / \mathrm{mol})$ & 13.29 & 26.81 & 3.16 & 11.60 & 19.12 & 10.7 & 10.46 & 15.14 & 10.9 \\
\hline$A\left(\min ^{-1}\right)$ & 102.22 & 57.29 & 0.34 & 110.29 & 69.39 & 6.92 & 115.14 & 76.11 & 25.4 \\
\hline$m$ & 0.03 & 0.05 & 0.00 & 0.03 & 0.05 & 0.00 & 0.03 & 0.05 & 0.00 \\
\hline$n$ & 2.00 & 0.21 & 1.41 & 1.15 & 0.32 & 2.4 & 1.12 & 0.39 & 2.78 \\
\hline$p$ & 0.55 & 0.32 & 0.00 & 0.60 & 0.50 & 0.00 & 0.65 & 0.57 & 0.00 \\
\hline SSD & 11.96 & 2.97 & 26.65 & 6.90 & 0.59 & 1.05 & 0.30 & 0.29 & 1.5 \\
\hline
\end{tabular}




\section{Discussion}

The pyrolysis of biomass generally occurs in three stages. This is due to the decomposition of its three main components, viz. hemicellulose, cellulose and lignin [27]. The first stage is predominantly dehydration, the second stage comprises active pyrolysis. The decomposition of hemicellulose and cellulose are grouped together here. The hemicellulose decomposition takes place first, followed by the decomposition of the cellulose $[6,16,27]$. Finally, in the third stage, termed passive pyrolysis, lignin (which is thermally more stable) decomposes. It can be observed from the TGA and DTG curves that the bamboo decomposition follows the trend of a typical TG curve of biomass pyrolysis in the literature [6] and the three stages are clearly observed (see

Figure 1 and Figure 2). The dehydration stage temperature differs for each heating rate with the maximum dehydration temperaturesbeing $81{ }^{\circ} \mathrm{C}$ for a heating rate of 20 ${ }^{\circ} \mathrm{C} / \mathrm{min}, 110.72{ }^{\circ} \mathrm{C}$ for the $100{ }^{\circ} \mathrm{C} / \mathrm{min}$ and $123.36{ }^{\circ} \mathrm{C}$ for 200 ${ }^{\circ} \mathrm{C} / \mathrm{min}$ heating rate. The maximum dehydration rates were $1.417,4.918$ and $8.828 \% / \mathrm{min}$ for the 20,100 and $200{ }^{\circ} \mathrm{C} / \mathrm{min}$ respectively. The second stage, the hemicellulose-cellulose decomposition of the bamboo is indicated by the slight shoulder in the DTG curve in Figure 2, similar to the literature. This shoulder is clearly visible for the heating rates of 20 and 100 ${ }^{\circ} \mathrm{C} / \mathrm{min}$. The decomposition temperatures obtained in this case fall within the temperature ranges reported in the literature. It was observed that as the heating rate increased, so did the temperature range of the hemicellulose and cellulose decomposition and this is ascribed to the endothermic nature of the decomposition. The shoulder in the DTG curves for the bamboo ranged between $250-312{ }^{\circ} \mathrm{C}$ for a heating rate of $20^{\circ} \mathrm{C} / \mathrm{min}$, and $280-348^{\circ} \mathrm{C}$ for a heating rate of $100^{\circ} \mathrm{C} / \mathrm{min}$. The peak was less visible at a heating rate of $200^{\circ} \mathrm{C} / \mathrm{min}$, believed to be masked by the fast heating rate, and instead a sharp smooth peak was obtained at temperatures between 290 and $440{ }^{\circ} \mathrm{C}$.

This sharp curve is associated with the decomposition of the cellulose and it can be said to be the maximum decomposition rate for the whole material. The maximum decomposition temperatures (maximum peak associated with cellulose decomposition) for the 20 and $100^{\circ} \mathrm{C} / \mathrm{min}$ heating rates were $353.7{ }^{\circ} \mathrm{C}$ and $380.67{ }^{\circ} \mathrm{C}$ respectively. The maximum decomposition rates obtained were 17.9, 97.4 and $192 \% /$ min for the heating rates of 20,100 and $200{ }^{\circ} \mathrm{C} / \mathrm{min}$ respectively.

Finally, in the third passive pyrolysis stage, the weight conversion happened at a rate between 1.84 and $1.57 \% / \mathrm{min}$ for the heating rate of $20{ }^{\circ} \mathrm{C} / \mathrm{min}, \quad 7.9$ and $0.166 \% / \mathrm{min}$ for the $100{ }^{\circ} \mathrm{C} / \mathrm{min}$ and 19.9 and $0.400 \% / \mathrm{min}$ for the $200^{\circ} \mathrm{C} / \mathrm{min}$.

From the TGA data along with the corresponding derivative Thermogravimetric (DTG) curves for bamboo (see

Figure 1 and Figure 2) we observe that the heating rate has several effects on the pyrolysis process [20]. As the heating rate increases the curve shifts towards high temperatures, hence the dehydration temperature obtained at a heating rate of $200{ }^{\circ} \mathrm{C} / \mathrm{min}$ was higher than that at 20 and $100^{\circ} \mathrm{C} / \mathrm{min}$. The heating rate also affects the starting and the final temperature for each the three stage (i.e. the dehydration, active, and passive pyrolysis stages).

The residues remaining after the carbon conversion stage for bamboo (at this point referred to as char) were found to be $21.5,19.6$ and $19.4 \%$ for the 20,100 and $200{ }^{\circ} \mathrm{C} / \mathrm{min}$, respectively and the difference in char yields are ascribed to the difference in samples sizes [22].

Observing the superimposed TGA and DTG curves at $200^{\circ} \mathrm{C} / \mathrm{min}$ for pine, peach pips, and Napier grass, along with bamboo (shown in

Figure 3 and Figure 4), we observe that the behaviour of these other three materials during pyrolysis is similar to that of bamboo, with slight noticeable differences.

The maximum decomposition rates obtained during $20{ }^{\circ} \mathrm{C} / \mathrm{min}$ is $12.5,17.9,18.9$ and $19.6 \% / \mathrm{min}$ for peach pips, bamboo, Napier grass and pine respectively. The pine showed the highest decomposition rate. The same trend was observed at $100{ }^{\circ} \mathrm{C} / \mathrm{min}$. Pine wood had the highest decomposition rate of $99.5 \% / m i n$ while peach pips had the lowest decomposition rate of $66.85 \% / \mathrm{min}$. However, when the heating rate was increased to $200{ }^{\circ} \mathrm{C} / \mathrm{min}$, Napier grass decomposed at the fastest rate of $266.8 \% / \mathrm{min}$.

Although Napier grass decomposed at the fastest rate, it had a low conversion (

Figure 3 ). The residues remaining at the end of the process were 12.4, 19.5, 21.2 and 26.6 mass percentage for pine, bamboo, peach pips and Napier grass respectively. These conversion correspond to those in the literature [11]. For all materials, a higher heating rate resulted in higher the conversion and $a$ faster the decomposition rate.

The desired products of the gasification process are hydrogen and carbon monoxide, with some carbon dioxide and hydrocarbons like methane also expected. The TGA characterisation experiments do not correspond exactly with what is happening inside gasifiers. It merely gives an indication as to what to expect.

Figure 5 shows the FTIR spectra for bamboo at a heating rate of $20^{\circ} \mathrm{C} / \mathrm{min}$. The first spectrum at $82^{\circ} \mathrm{C}$ corresponds to the dehydration stage. It can be seen from the spectrum that predominantly water peaks appear at this point, at wave numbers of $\sim 3600$ and $\sim 1500 \mathrm{~cm}^{-1}$, with some carbon dioxide observed at $2380 \mathrm{~cm}^{-1}$. The heating rate was observed to have no significant qualitative effect on the gasses produced during dehydration.

During active pyrolysis, the carbon dioxide peaks immediately become more prominent (second and third spectra). A secondary $\mathrm{CO}_{2}$ peak at $670 \mathrm{~cm}^{-1}$ becomes more clearly observable. The other noticeable peak at $1800 \mathrm{~cm}^{-1}$ is attributed to aldehydes. Though it is relatively small compared to other peaks, the carbon monoxide peak is observed at $2150 \mathrm{~cm}^{-1}$. The process parameters (such as residence time, equivalent ratio, feeding rate, etc.) which have an effect on $\mathrm{CO}$ yield, were not 
manipulated to maximise the yield. The fourth spectrum in Figure 3 belongs to the passive pyrolysis stage associated with lignin decomposition. Mostly $\mathrm{CO}_{2}$ gas is released during this stage.

In addition a methane peak was observed at $3000 \mathrm{~cm}^{-1}$ while other alkanes were observed at $1200 \mathrm{~cm}^{-1}$. Methane and other hydrocarbons are known to be the main products of fast pyrolysis operated at temperatures up to $500^{\circ} \mathrm{C}$ with short residence time $(\sim 1 \mathrm{sec})$. Their presence during the TGA decomposition of biomass material is thus expected. Integrated peak areas for experiments conducted under heating rate of $200^{\circ} \mathrm{C} / \mathrm{min}$ are listed in Table1, for semi-quantitative comparison in the active pyrolysis stage. In all cases the partial pressure trend is: $\mathrm{CO}_{2}>\mathrm{CH}_{4}>\mathrm{H}_{2} \mathrm{O}>\mathrm{CO}$.

The kinetic parameters for all the cases investigated are listed in Table 3, Table 4, Table 5 and

Table 6.

The extent of conversion for bamboo, heated at 20 $\mathrm{C} / \mathrm{min}$, for the total reaction as well as for the individual thermal events, is presented graphically in Figure 6. Visually the model is a reasonable fit in all cases. The trend for the magnitude of the activation energy is that it is smallest for the first dehydration stage; possibly because the event may be driven by heat transfer effects rather than pure chemical kinetics, and that all values decrease as the heating rate increases.

\section{Conclusions}

The peach pips, Napier grass, pine and bamboo were characterised using TGA-FTIR under a flowing nitrogen atmosphere. Pyrolysis was confirmed to be a three-step process, viz. evaporation of moisture contained in the material, followed by the decomposition hemicellulose/cellulose and then lignin. In the peach pips the hemicellulose and cellulose decomposition peaks are clearly separated, whereas in other materials the peaks of these two components are seen as one large peak with a small shoulder, indicative of hemicellulose decomposition. This could be due to the fact that the ratios of these components differ per material. Although they were not determined for this purpose of study, based on the DTG curves it may be assumed that peach pips has higher percentage of hemicellulose than other three selected biomass materials. Furthermore the peak representing the decomposition of hemicellulose and cellulose in Napier grass is very sharp and could be regarded as an indication of very low percentage of hemicellulose contained in Napier grass. This agrees with the literature [15] The lignin decomposition in both material takes place slowly in the range $160-900{ }^{\circ} \mathrm{C}$. Napier grass was also found to have high amount of residues remaining after pyrolysis process ( 26\%). This could be due to the fact that most grasses contains high level of silicon which is used as a defense against herbivores and voles [13]. Pine was found to have the lowest residue remaining ( 12\%).

Gasses released during TGA experiment were $\mathrm{H}_{2} \mathrm{O}$, $\mathrm{CO}_{2}, \mathrm{CO}, \mathrm{CH}_{4}$ and other groups of hydrocarbons. Hydrogen is also a product of gasification but it is not detectable by FTIR. The percentage yield of these products depends on the operating parameters of the gasification reactor. The desired products of gasification are $\mathrm{H}_{2}$ and $\mathrm{CO}$. The activation energies of each material vary throughout as function of heating rate. The dehydration step has a lower activation energy than the active and passive pyrolysis steps, probably due to the fact that the process resembles evaporation more than a chemical reaction

\section{Acknowledgements}

The authors express their gratitude to the following organizations for funding and support of this work: South African Nuclear Corporation; the National Research Foundation; and the Department of Science and Technology.

\section{References}

[1] R. Bassilakis., R.M. Carangelo., M.A. Wojtowicz. (2001). TGFTIR analysis of biomass pyrolysis. Fuel, 80 (12), 1765-1786.

[2] G.r. Berndes., M. Hoogwijk., R. van den Broek. (2003). The contribution of biomass in the future global energy supply: a review of 17 studies. Biomass and Bioenergy, 25 (1), 1-28.

[3] M.E. Brown., M. Maciejewski., S. Vyazovkin., R. Nomen., J. Sempere., A. Burnham., J. Opfermann., R. Strey., H.L. Anderson., A. Kemmler., R. Keuleers., J. Janssens., H.O. Desseyn., C.-R. Li., T.B. Tang., B. Roduit., J. Malek., T. Mitsuhashi. (2000). Computational aspects of kinetic analysis: Part A: The ICTAC kinetics project-data, methods and results. Thermochimica Acta, 355 (1-2), 125-143.

[4] G. Chen., J. Andries., Z. Luo., H. Spliethoff. (2003). Biomass pyrolysis/gasification for product gas production: the overall investigation of parametric effects. Energy Conversion and Management, 44 (11), 1875-1884.

[5] H.L. Chum., R.P. Overend. (2001). Biomass and renewable fuels. Fuel processing technology, 71 (1), 187-195.

[6] L. Gašparovič., Z. Koreňová., L'. Jelemenský. (2010). Kinetic study of wood chips decomposition by TGA. Chemical Papers, 64 (2), 174-181.

[7] P. Ghetti., L. Ricca., L. Angelini. (1996). Thermal analysis of biomass and corresponding pyrolysis products. Fuel, 75 (5), 565573.

[8] Z. Hui., Y. Huaxiao., Z. Mengmeng., Q. Song. (2010). Pyrolysis characteristics and kinetics of macroalgae biomass using thermogravimetric analyzer. Proc World Acad Sci Eng Technol, 65 1161-1166.

[9] A. Khawam., D.R. Flanagan. (2005). Role of isoconversional methods in varying activation energies of solid-state kinetics: I. Isothermal kinetic studies. Thermochimica Acta, 429 (1), 93-102.

[10] A. Khawam., D.R. Flanagan. (2006). Solid-state kinetic models: basics and mathematical fundamentals. The Journal of Physical Chemistry B, 110 (35), 17315-17328. 
[11] A. Kumar., L. Wang., Y.A. Dzenis., D.D. Jones., M.A. Hanna. (2008). Thermogravimetric characterization of corn stover as gasification and pyrolysis feedstock. Biomass and Bioenergy, 32 (5), 460-467.

[12] K.G. Mansaray., A.E. Ghaly. (1999). Determination of kinetic parameters of rice husks in oxygen using thermogravimetric analysis. Biomass and Bioenergy, 17 (1), 19-31.

[13] F.P. Massey., S.E. Hartley. (2006). Experimental demonstration of the antiherbivore effects of silica in grasses: impacts on foliage digestibility and vole growth rates. Proceedings of the Royal Society of London B: Biological Sciences, 273 (1599), 2299-2304.

[14] P. McKendry. (2002). Energy production from biomass (part 1): overview of biomass. Bioresource technology, 83 (1), 37-46.

[15] I.Y. Mohammed., Y.A. Abakr., F.K. Kazi., S. Yusup., I. Alshareef., S.A. Chin. (2015). Comprehensive Characterization of Napier Grass as a Feedstock for Thermochemical Conversion. Energies, 8 (5), 3403-3417.

[16] E.L.K. Mui., W.H. Cheung., V.K.C. Lee., G. McKay. (2008). Kinetic study on bamboo pyrolysis. Industrial \& Engineering Chemistry Research, 47 (15), 5710-5722.

[17] A. Nahman., W. de Lange., S. Oelofse., L. Godfrey. (2012). The costs of household food waste in South Africa. Waste management, 32 (11), 2147-2153.

[18] L. Perez-Maqueda., J. Criado., P. Sanchez-Jimenez. (2006). Combined kinetic analysis of solid-state reactions: a powerful tool for the simultaneous determination of kinetic parameters and the kinetic model without previous assumptions on the reaction mechanism. The Journal of Physical Chemistry A, 110 (45), 12456-12462.
[19] T.B. Reed., A. Das. Handbook of Biomass Downdraft Gasifier Engine Systems. Golden, Colorado. Biomass Energy Foundation; 1988.

[20] S. Şensöz., M. Can. (2002). Pyrolysis of pine (Pinus brutia Ten.) chips: 1. Effect of pyrolysis temperature and heating rate on the product yields. Energy Sources, 24 (4), 347-355.

[21] K. Slopiecka., P. Bartocci., F. Fantozzi. (2012). Thermogravimetric analysis and kinetic study of poplar wood pyrolysis. Applied Energy, 97 491-497.

[22] M. Stenseng., A. Jensen., K. Dam-Johansen. (2001). Investigation of biomass pyrolysis by thermogravimetric analysis and differential scanning calorimetry. Journal of Analytical and Applied Pyrolysis, 58 765-780.

[23] S.V. Vassilev., D. Baxter., L.K. Andersen., C.G. Vassileva. (2010). An overview of the chemical composition of biomass. Fuel, 89 (5), 913-933.

[24] S. Vyazovkin., A.K. Burnham., J.M. Criado., L.A. PérezMaqueda., C. Popescu., N. Sbirrazzuoli. (2011). ICTAC Kinetics Committee recommendations for performing kinetic computations on thermal analysis data. Thermochimica Acta, 520 (1-2), 1-19.

[25] S. Vyazovkin., C.A. Wight. (1999). Model-free and modelfitting approaches to kinetic analysis of isothermal and nonisothermal data. Thermochimica Acta, 340-341 53-68.

[26] T. Wongsiriamnuay., N. Tippayawong. (2010). Nonisothermal pyrolysis characteristics of giant sensitive plants using thermogravimetric analysis. Bioresource technology, 101 (14), 5638-5644.

[27] H. Yang., R. Yan., H. Chen., D.H. Lee., C. Zheng. (2007). Characteristics of hemicellulose, cellulose and lignin pyrolysis. Fuel, 86 (12), 1781-1788.

[28] X. Zhao., D. Du. (2015). Forecasting carbon dioxide emissions. Journal of Environmental Management, 160 (0), 3944. 